\title{
COMBINING PEDAGOGICAL STRATEGIES AND ICT SUPPORT FOR FOSTERING THE DIGITALIZED AGENTIC LEARNER
}

\author{
Bernhardsson L. Vallo Hult H. Gellerstedt M. \\ lennarth.bernhardsson@hv.se, University West (SWEDEN) \\ helena.vallo-hult@hv.se, University West (SWEDEN) \\ martin.gellerstedt@hv.se, Univeristy West (SWEDEN)
}

\begin{abstract}
Higher education is facing exceptional challenges due to an increased complexity on the labour market. The work life of today is highly specialized and demands continuous education, i.e. lifelong learning. Higher education must focus on developing competencies for work life, beyond traditional theoretical knowledge [1]. To cater for these demands, higher education must adopt more applicationoriented and trans-disciplinary research [2]. Moreover, colleges and universities could more systematically take responsibility for career development and adjust curricula for both traditional and non-traditional students [3]. A crucial question to address is how higher education could foster a student to become a "lifelong learner"? From a pedagogical perspective, it is of course vital to teach a student how to learn [4], aiming at achieving the skill to become a self-directed learner. Interestingly, it is argued that the qualities for being a proactive and agentic learner in higher education are the very same abilities required for effective professional practice [5]. We need to use educational strategies, e.g. work-integrated learning (WiL), as a part of the preparation of becoming an agentic learner, that permit them to successfully negotiate, engage and learn from what they are afforded, for both personal and professional outcomes [6]. Furthermore, we need to adopt important key factors that support fostering agentic learners [7].
\end{abstract}

In parallel to pedagogical strategies and key factors, Information and Communication Technology (ICT) could play an important role for continuous learning [8-10]. Research shows that over the recent years, social media has been pointed out as a tool, not only for external communication, but also for informal learning within organizations [11-14].

In this paper we wish to suggest a combination where important pedagogical strategies are combined with ICT-support. Moreover, we wish to suggest a strategy for how this combination could be practiced in higher education, making the transfer to work life smoother.

We acknowledge that students of today most often have good knowledge of the use of various digital tools such as Facebook, Youtube etc. This is however often constrained to the use of various platforms and tools for entertainment and social contacts. How these tools can be used for learning portfolios, both during their studies and for lifelong learning, is less known and used. We suggest that students during their education choose digital tools based on individual preferences and build a personal learning environment (PLE) [15]. The PLE should include "open tools", such tools are available outside closed systems within organizations, in order to be useful also after graduation. The student has the possible to develop and re-use knowledge of tools and platforms to work in the new context, working life. However, the use of a PLE will not in itself do the trick.

Portfolio is one of many tools to assess learning. When the digital development progressed and applications on the Internet has expanded, the portfolio characteristics can be changed to the eportfolio [16]. We advocate that both teachers and student need support for developing pedagogical strategies that optimize the use of ICT and aims at fostering agentic learners. We suggest that an eportfolio may constitute such a joint support.

In this paper we will show that an e-portfolio and PLE can support important factors for fostering agentic learners who in an efficient way take advantage of modern ICT. In sum, we suggest an approach for fostering "digitalized agentic learners".

Keywords: e-portfolio, work integrated learning, agentic learner 


\section{INTRODUCTION}

The knowledge and emerging innovation society and rapid development of information and communication technology implies continuous changes and conditions in working life demanding continuous learning for keeping up to date. Higher education must focus on developing competencies, beyond traditional theoretical knowledge, adjusted for this complex work life [1]. Universities struggles with balancing traditional academic values such as autonomy and academic freedom with marketization and adjustments to needs generated by the surrounding society [17]. One way of strengthening the "third mission" for higher education, i.e. cooperation between universities and surrounding society, is to adopt more application-oriented and trans-disciplinary research [2]. Moreover, colleges and universities could more systematically tale responsibility for career development and adjust curricula for both traditional and non-traditional students [3].

One important issue is to develop strategies that makes the transitions from education to work life as smooth and efficient as possible. Furthermore, the highly specialized and rapidly changing society of today emphasize the importance of lifelong learning, more than ever. Consequently, one of the most important challenges for higher education is to find strategies for fostering students to become efficient lifelong learners. Clearly, the relatively short period that a person undergoes higher education is a very limited time of the whole carrier. From this perspective learning at workplaces deserves more attention, and there is a call for increased conceptualization and development of curriculum also for work place learning [18]. From a pedagogical perspective, it is vital to teach a student how to learn [4], aiming at achieving the skill to become a self-directed learner. Interestingly, it is argued that the qualities for being a proactive and agentic learner in higher education are the very same abilities required for effective professional practice [5].

The crucial question to address is how to make transition smooth and to foster lifelong learners There is a call for specially designed curriculum and educational strategies, e.g. work-integrated learning [6]. Furthermore, it is crucial to identify and support key factors that support fostering learners to be agentic [7], highlighted in educational research.

In parallel to pedagogical strategies and key factors studied in educational research, information systems research shows that information and communication technology (ICT) could play an important role for continuous learning [8], especially informal learning [9, 10, 19]. Research shows that over the recent years, social media has been pointed out as a tool, not only for external communication, but also for informal learning within organizations $[11,13,14]$. Apparently, educational research and information system research seems to have common grounds.

The aim with this paper is to discuss common grounds within educational and information system research. Moreover, we wish to suggest how ICT could be used in practice as support in higher education and work life, underpinning a career and a life as an agentic lifelong learner.

\subsection{Work integrated learning ad modum University West}

University West in Sweden is since 2002 commissioned by the government to develop strategies for work-integrated learning (WIL). Higher education institutes are expected to interact with the surrounding society. University West regards WIL as an ideology that permeate the universities activities in its whole. This means that pedagogical methods are based on WIL and are systematically further developed in order to maximize the students' opportunities to integrate knowledge based on theory with experience based knowledge. Furthermore, the university is pro-active in research and development projects aiming at developing learning at workplaces. This is done in a co-creation manner, with companies and organizations; and since 2011 it is possible to take a doctoral degree in WIL.

To be more precise, in undergraduate education the following strategies could serve as exemplifications. Co-operative education (Co-op), where courses are sandwiched with periods of paid work, has been applied by University West already from the origin 25 years ago. Beyond these specially designed programs, other WIL-activities in courses could for instance consist of the following four categories [20]. Firstly using practice as inspiration by using case methodology, practice based simulations or role play, secondly bringing practice to class, e.g. guest lectures or using work life material like professionally developed programing code, annual reports and so forth. Thirdly, utilizing professional tools, e.g. using the same software as companies or adopting industry standard for working processes. Finally, bringing class to practice in different forms of field work, project works, thesis work, and longer co-op periods. The PhD-program is also based on WIL not only as an aim for 
the research projects, but also as a pedagogical approach. Research is done in close proximity with surrounding society and the pedagogical approach underpinning the program is also based on WILfashion, with an emphasis on learning outcomes important for being a researcher. For instance, different research methods are not divided into separate courses (e.g. qualitative vs quantitative methods), instead the course is based on the research process, from formalizing a research question to presentation of result. In each step different choices, e.g. qualitative, quantitative or mixed design, are discussed, aiming at resembling a research process as it is done in practice. More concrete examples of how WIL is practiced in undergraduate courses, PhD-program and in research programs is described elsewhere [6].

In sum, using WIL as an ideology means that all efforts is put in place for maximizing the synergy achieved by mixing theory and practice and thereby maximizing learning the content of a course of educational program.

One might say that WIL is about decreasing the gap between theory and reality. The reality for higher education is that students actually have a lot of other options for learning the content in a course content other than the resources given by the University. There are many examples of courses were students find interesting reliable and trustworthy information elsewhere, this could be online teaching material, interviews and material from companies and organizations illustrating the theory set into practice, videos or social media with intensive debates and exchange of experiences. In many cases such material enrich a course and gives learning possibilities for both student and teachers as well. This is a good example of a way of learning that is transferrable - possible to use in higher education and on work places, as well. Such co-creation are especially notable in online courses were participants on different work places could interact and share experiences with each other and with other students still under education.

It is worth pointing out that our efforts with WIL both is about developing and refining pedagogical strategies for optimizing the students chances to actually learning the educational content, but we are also focusing on the learning process in itself, with the ambition to learn the students how they learn and which support that are fruitful to use in education and on work place. Altogether these efforts diminish the difference between learning in higher education and in work places.

\subsection{Agentic Learner}

From a pedagogical perspective, it is of course vital to teach a student how to learn [4], aiming at achieving the skill to become a self-directed learner. Interestingly, it is argued that the qualities for being a proactive and agentic learner in higher education are the very same abilities required for effective professional practice [5] as a part of the preparation of becoming an agentic learner, that permit them to successfully negotiate, engage and learn from what they are afforded, for both personal and professional outcomes.

Richards et al. (2014) describe agentic learners with five different aspects [7]. These aspects are; understanding how to use and extend their personal epistemology, maximizing opportunities in their self-directed learning environment, developing a positive sense of self, employing assertiveness and resilience through peer collaboration. A prerequisite for an agentic learner is ability to understand their own view of what is knowledge and thereby be able to see and describe how the knowledge can be developed.

For the development of the personal knowledge, students need ideal conditions so they could develop their own environment for learning. Their own environment is necessary for them for self-directing learning, so they can create a personalized view of what's been learned and make visible their knowledge needs for the future.

Students describe that they learn best when they are given good support in various forms of collaboration. It also creates a sense of value for their own knowledge and as an individual. To encourage learners to identifying their own values and reflect on how and maybe why they are different from the values of others, creates good conditions for engagement. 


\subsection{Social Cultural Perspective, Connectivism}

One of the most widespread theories of learning is the socio-cultural perspective (Säljö, 2005) that was founded long before the digitization and access to the Internet. This also applies to many other theories of learning; which were developed before the technology had impact on learning. The basis of many learning theories is that new knowledge is built by individuals in interaction with others and through personal reflection [e.g. 21].

Connectivism is a learning theory by Stephen Downes and George Siemens who take earlier theories into account and adds access to information and communications technology [22].

Siemens lists some specific trends for learning in the digital era [22]. Some of these trends are:

- Informal learning is an equally important part of the knowledge formation as formal learning and education

- Learning is an ongoing process and we have to learn how to learn and use application witch support learning to create a lifelong learning

- Learning takes place in many different ways. Through participation in communities of practice, through personal networks and contacts, and by the challenges of work-related tasks

- Technology have effect on our brains. The tools we use also impact on how we think.

- Know-how and know-what and expanded with know-where. It is important to know where and how the information can be found

\section{PORTFOLIO IN EDUCATION}

An educational portfolio is typically a systematic collection of writing and different forms of evidence gathered for diverse purposes. It offers students a concrete opportunity to value their own work, while teachers can evaluate the work and provide feedback [23].

Some objectives may be to demonstrate the learning outcomes, showing that the student meets the objectives and academic requirements for a course, demonstrate an understanding of the process of learning, creating an archive of their results. But also a place for communication and reflection with their fellow students and teachers.

\section{1 e-Portfolio}

e-Portfolio is sometimes described as a digital version of the traditional portfolio. But with the right tools it can simultaneously provide expanded opportunities. For example, a note, or text can be tagged with topics, themes that can tie together many different sections and materials with each other by precisely the theme that the text has been labeled with. Then divide the portfolio into different sections such as private, personal and public, and using labeling in all sections, the individual student will get an overview of all material on a theme or topic.

The choice of tools will also make it possible to collect and store user-generated material and then maybe pick another tool for curating links and documents from a personalized flow of information retrieved from the Internet. By using the same materials and labeling materials linked together in both the personal archive and curated materials. By collecting material with cohesive tags facilitated both the experience and judgment of the individual's progression in their learning. Through retrospective reflection and consideration, the differences visible between the initial work and the level of knowledge that exists today.

Digital solutions provide new opportunities by a single material can be in several different contexts without the need for multiple copies. So if a text evolve and change, these changes will be visible in all the contexts where the text has a marking substance. Features and capabilities can always be developed by individual adds new alternative tools designed for new features in the student's personal portfolio. By using the tools and programs that are free or otherwise available on the web creates a personalized and modular portfolio [24]

Hughes (2000) argues in her dissertation on the importance of the introduction of technology in teaching creates something new [25]. New conditions to perform or present something in a way that is not possible without the technology. She describes three different levels Replacement, Amplification and Transformation, the RAT-framework. Replacement means that technology only replace the analog 
with a digital solution. Nothing else changes. Amplification increases efficiency, productivity, and facilitates the transfer of information and instructions. The third level is the transformation that creates entirely new opportunities for both learning and curricula.

\subsection{The book of thought's}

Perneman (2000) writes in his essay "Thought book - a form of experience and reflection design" [26] that thoughts and reflections can be divided into three different categories, private, personal and public. The private is only for the user, no one else can access these areas, the public level consists of the material published so that everyone has access to the material and media stored or published on this level. On the personal level of control users who or who has access to read and comment. The private part consisting of short thoughts and notes that are of such a nature that the individual does not want to share them to someone else. They can still be valuable to understand how one has thought and reasoning about different events and situations. "Thought book" can be an educational tool, and the division into the three levels is a form of construction that helps to organize thoughts. Sometimes it may be necessary that the thoughts are given a structure already in advance and sometimes the thoughts is given a structure and context in retrospect.

If a portfolio is seen in the equivalent manner and divided into similar levels get the private individual's own collection of thoughts, reflections and materials. These could then be developed and refined in order to function as and presented as personal. These personal reflections can be shared with others, perhaps a smaller group of people, such as fellow students, colleagues or teachers. Reflections and text can serve as a basis for peer discussions or as part of an element of the examination in a course.

\subsection{Collaboration}

An e-portfolio needs to have many functions in which one of the most important, to act as a tool of knowledge development, is to support various forms of cooperation and communication. A text that is moved from the private level to the personal or joint can be assigned permissions to fellow students and teachers to peer review or comment for the continued development of the text. Text or materials can only be assigned permissions teacher assessment in connection with an examination or to provide feedback.

\subsection{Curation}

Additional functions in a portfolio can be to collect curated materials, links and content from the Internet. It may to some extent be automated through the subscription of feeds but also the collection of downloaded content and links can be placed in the part of a portfolio relating curation of external material. These collected texts, links, etc. can be given a label or tag that links it together into the themes and topics that the portfolio contains. This is to make them searchable and linked in the same way as personally produced content are tagged in order to provide a comprehensive view of both created and curated content.

\section{PERSONAL LEARNING ENVIRONMENT \& NETWORK}

Personal Learning Environment (PLE) is not defined as an application. Instead, it is the total amount of tools that we use for our learning [15]. Many of these tools are now digital and have different features for communication and collaboration. More of them can be counted to those who we call social media. Others might not be social but acts more like a surface or place to store information. Applications for storing given more and more features similar to those in the social media which makes them difficult to distinguish but it also gives the opportunity to share some of the material stored on these sites. By sharing and Collaborate with others around the material that an individual has saved in its curation, whether the person save others, Consuming, or if there are things that you have produced is the individual or the student both the producer and the consumer; procumer.

PLE has been strongly linked with Personal Learning Network (PLN) and consists of individuals, feeds and websites where individuals draw their information. It is also the network of people to communicate and discuss with around different topics. The tools that the individual chooses to use in their PLE often support contacts with networks of people, gathering data and information. The possibility to choose tools to use in a PLE and adapt the use of these programs for the unique needs rather than the needs adjusted to the system as it is when someone creates a particular application and requires that learners will use it for their own portfolio. 


\subsection{Expanding network and flow of feeds}

For lifelong learning requires the active work to both maintain and expand the network and application choices. Regular reflection on their own knowledge and their knowledge needs, which is one of the basics of portfolio method, one can find a need to expand both networks and tools to use. Such work fits well with some of the principles of connectivism. Siemens describes connectivism and networking that learning is a process of seeing and creating linkages to various sources of information and the maintenance and nurturing of existing nodes in the network is necessary to promote a continuous learning process [22].

An ongoing search for places and people you follow through their applications is essential both for students and people in the workplace. Such can be done by probe the people and places in the network and see who they follow. For example, it is easy to follow people in a subject on Twitter, and then see what other twitter users that they follow. Placing them in their own flow and then see who they follow, etc., and maybe even add a selection of these expanding flow of information in the subject. Then use some tool to collect links from these users and add them to their own curation will provide a good basis for further learning and development.

\section{ARE THE THEORIES SINGING THE SAME TUNE?}

Based on the requirements of the knowledge society of today and results from educational research described above, we suggest that the following components constitutes important cornerstones for fostering agentic lifelong learners. To begin with, one aspect of learning is continuity. No matter if we conceptualize learning into formal vs informal learning it is a fact that learning is an ongoing continuous process. It is also pointed out that the highly specialized labor market of today demands continuous learning for keeping up to date, which in some sense demands that the continuous process should be controlled and optimized, i.e. a call for a continuous curriculum as a formalized lifelong learning. The second cornerstone we suggest is to diminish the gap between higher education and work life, for instance by adopting WIL. Learning and work should not be regarded as separate and different phases in a person's life, instead learning and work, theory and practice, should go hand in hand, all the way from education throughout the working career. Previous research also points out that the characteristics of a successful student is in line with the characteristics need for successful professional practice [5].

The third cornerstone is reflection of the cognitive process. To support and develop cognitive selfguidance, i.e. to learn how to learn and to enable the possibilities to take control of possible actions and direct future development is an important meta-outcome of higher education. We also believe that reflection can be related to personal characteristics, like self-efficacy.

As our fourth cornerstone we suggest communication and thereby collaboration, with mentors, supervisors and peers. Informing Science [27] describes features that very well match the needs of a portfolio. Informing system includes three components, both the sender as an information environment and a system or tools for transfer and finally a system in which students are given the opportunity to present and discuss the learning outcomes. Such elements should also be in a proper functioning of the portfolio.

Finally, as our fifth cornerstone we suggest that personalization in the sense that within a learning context there must be a possibility for individual choices based on interest and intentions. We believe that leaving the one-size-fit-all teaching design in favor of the learner-centric approach and opportunity to nurture and enrich personal interests is essential for engagement which in turn is essential for learning.

We will now discuss how these five cornerstones are related to ICT-research, especially e-portfolio and PLE.

By using publicly available tools and applications, the transformation between studies and work will be smoother since the student simply can go on using the same tools at the workplace, which creates the opportunity for continuity. At the same time, the tools can be tested, selected and you can get the chance to practice on the use in connection with university studies. Students learn the tools for their own needs related to the topic they are studying with a focus to learn the subject and not a specific orientation courses in how to use the tools. During their studies, students may participate in different groups, but especially in the community, which consists of the other students. The different courses can point to the necessary feeds the studies required to then personally increase the number of 
subscriptions to channels of information. The courses' distinct needs and then expansion of information feeds for personal and critical choices, to their own PLE, provides ample opportunity for a smooth transition between formal learning and the learning that is required in the workplace.

Our daily intake of news often include use of several different media. For example, we read maybe a morning paper and then listen to the radio news when we commute to later in the evening watching the TV news. Then add more magazines, perhaps digital from other parts of the world, may follow a recent podcast, etc. we create a richer picture of what is happening in the world. In the same way a student can begin with the information sites as required in a course and then add their own channels selected to suit the different tools and added the PLE or in its portfolio.

Such gradual expansion of information channels can be supported by different elements in teaching and lead to the borders between the theoretical part of the studies and the practical steps in professional life diminish. Theory and practice are inseparable and become sustainable, interconnected over time. An increased use of Open Educational Resources (OER) creates an understanding of the needs and the ability to use more sources than study literature. Links to such materials together with their personal learning outcomes that are placed in the personal portfolio can be tagged with searchable tags and can be in the portfolio given a common context that can be used for retrospective reflection on the student's development. Even comments from peers and own participation in the forum or the giving comments to others can be tagged and included in the personal curation.

A portfolio and PLE are divided into three levels, private, personal and public. Where mainly the personal part of the "system" refers to a dialogue and collaboration while the public can provide the opportunity for a wider audience to comment. The levels to be used for communication and cooperation should be chosen to provide a feed in the form of Really Simple Syndication (RSS), which makes it possible to follow feeds from a group of students from both other students, peers, supervisors and teachers. By subscription of feeds rise to various content channels from both professional communicators and students or colleagues at work and can help to diminish the boundaries between higher education and working life.

The personalized e-portfolio include the possibility of making personal and critical selection of sources which creates the conditions for "long-tail learning", i.e. also learn theories that may depart rather heavily from the core of the course content and may be of interest for only a few persons. If parts of PLE consists of common tools provides an opportunity for awareness of the communities, such as student group, colleagues, included in the personal network. With support for awareness and subscriptions to RSS feeds, many of today's tools are provided with push functionality that further enhances the feeling of the personal PLE is part of a larger learning context. These opportunities are difficult to arrange without the digital tools and means that an e-portfolio can be made so that it is transformative in relation to the analog portfolio. A transformative portfolio is strong support for agentic learners.

\section{CONCLUSION}

Learning is an individual process, in conversations and collaboration with other individuals who learn. With that as a basis, it will be important to see the need for personal on tools that meet the supporting needs for communication, information gathering, storage etc. While the tools used in the Higher Education also be used after completing their studies to create long-tail-learning, the choice of applications based on personal preferences and needs. Many universities now use their own so-called Learning Management System (LMS), and these systems are rarely supportive of the features needed for student's personal needs and learning. They can also be very rarely used after completing their studies and it is then questioning why a student should learn how to use these tools when such knowledge cannot be used in the workplace. They are only administrative functions of the university. It is not uncommon for the working life organizations and companies are investing heavily in creating the internal system of competence sharing and storage. An institution that prepares individuals for the use of tools that are chosen based on personal needs do not need such investments for their learning.

A well-built e-portfolio using applications available outside the university offers more opportunities and increases the likelihood of a learning individual can continue to use and develop its portfolio of learning. The portfolio that diminish the boundaries between formal learning and the learning that is needed in the workplace improves the likelihood that the student will use it as a lifelong learning tool. 
The e in e-portfolio signalling a digitizing the idea of a digital portfolio and it is something other than an ordinary portfolio. For the long use, it is important that digitization is not just a replacement (Replacement) for the analogue without the need to alter the working (Transformation) in teaching and student learning. It is necessary at the same time continuity in the use of the portfolio as a tool both to gather information and ideas, to share it with others for common reflection and simultaneously recognize and highlight the new knowledge.

Continuous development of the personal portfolio, both in terms of tools and working methods that links to a growing network with increased information flow where the reflections are shared and discussed, provides good conditions for a long-tail-learning (LTL) can turn into a lifelong learning (LLL) with agentic learners using the e-options, i.e. as digitalized agentic learners. With a combination of different teaching strategies that create a transformative approach, and the personal choice and adaptation of digital tools, we provide learning opportunities for individuals to become Agentic Learners, both as a student and as an employee in professional life.

\section{REFERENCES}

[1] R. Barnett, "University knowledge in an age of supercomplexity," Higher education, vol. 40, no. 4, pp. 409-422, 2000.

[2] H. Nowotny, P. Scott, and M. Gibbons, Re-thinking science : knowledge and the public in an age of uncertainty, Cambridge: Polity Press, 2001.

[3] K. Betts, M. Lewis, A. Dressler et al., "Optimizing learning simulation to support a quinary career development model," Asia-Pacific Journal of Cooperative Education, vol. 10, no. 2, pp. 99-119, 2009.

[4] G. Gibbs, "Teaching Students to Learn: A Student-Centered Approach," 1981.

[5] S. Billett, "Realising the educational worth of integrating work experiences in higher education," Studies in Higher Education, vol. 34, no. 7, pp. 827-843, 2009.

[6] M. Gellerstedt, K. Johansson, and T. Winman, "Work Integrated Learning: a Marriage Between Academia and Working Life," Journal of Systemics, Cybernetics and Informatics, vol. 13, no. 6, pp. 38-46, 2015.

[7] J. Richards, L. P. Sweet, and S. Billett, "Preparing medical students as agentic learners through enhancing student engagement in clinical education," 2013.

[8] European Commission, The use of ICT to support innovation and lifelong learning for all - $A$ report on progress, 2008.

[9] C. Hague, and A. Logan, "A review of the current landscape of adult informal learning using digital technologies," Educational Research, 2009.

[10] S. Za, P. Spagnoletti, and A. North-Samardzic, "Organisational learning as an emerging process: The generative role of digital tools in informal learning practices," British Journal of Educational Technology, vol. 45, no. 6, pp. 1023-1035, 2014.

[11] M. J. Brzozowski, T. Sandholm, and T. Hogg, "Effects of feedback and peer pressure on contributions to enterprise social media," in Proceedings of the ACM 2009 international conference on Supporting group work, 2009, pp. 61-70.

[12] A. El Ouirdi, M. El Ouirdi, J. Segers et al., "Employees' use of social media technologies: a methodological and thematic review," Behaviour \& Information Technology, vol. 34, no. 5, pp. 454-464, 2015.

[13] P. M. Leonardi, M. Huysman, and C. Steinfield, "Enterprise social media: Definition, history, and prospects for the study of social technologies in organizations," Journal of ComputerMediated Communication, vol. 19, no. 1, pp. 1-19, 2013.

[14] D. Song, and J. Lee, "Has Web 2.0 revitalized informal learning? The relationship between Web 2.0 and informal learning," Journal of Computer Assisted Learning, vol. 30, no. 6, pp. 511-533, 2014.

[15] G. Attwell, "Personal Learning Environments-the future of eLearning?," Elearning papers, vol. 2, no. 1, pp. 1-8, 2007. 
[16] K. Chantanarungpak, "Using E-Portfolio on Social Media," Procedia-Social and Behavioral Sciences, vol. 186, pp. 1275-1281, 2015.

[17] S. Westa, "Balancing Traditional Academic Values And Modernization In European Higher Education: A Case Study Of The University Of Bologna."

[18] S. Billett, "Constituting the workplace curriculum," Journal of curriculum studies, vol. 38, no. 1, pp. 31-48, 2006.

[19] Ö. K. Yaşar, Şirin, "The power of social media in informal learning," Education in a Technological World: Communicating Current and Emerging Research and Technological Efforts, Formatex, Badajoz, 2011.

[20] B. Kjellén, and L. Svensson, "Work-Integrated Learning in the Classroom," in WACE 10thInternational Symposium on Cooperative \& Work-Integraded Education. Trollhättan, Sweden, 2014.

[21] D. A. Schön, The reflective practitioner : how professionals think in action, New York: Basic Books, 1983.

[22] G. Siemens, "Connectivism: A learning theory for the digital age," International Journal of Instructional Technology and Distance Learning, vol. 2, no. 1, 2005.

[23] V. Klenowski, S. Askew, and E. Carnell, "Portfolios for learning, assessment and professional development in higher education," Assessment \& Evaluation in Higher Education, vol. 31, no. 3, pp. 267-286, 2006.

[24] M. Kalz, "Building Eclectic Personal Learning Landscapes with Open Source Tools," Open Source for Education in Europe, Research \& Practise, F. De Vries, G. Attwell, R. Elferink et al., eds., Heerlen, The Netherlands, 2005.

[25] J. E. Hughes, Teaching English with technology: Exploring teacher learning and practice, 2000.

[26] J.-E. Perneman, "Tankeboken-en form för erfarenhetens och reflektionens gestaltning," Undervisning och lärande, pp. 32, 2000.

[27] E. Cohen, "Reconceptualizing information systems as a field of the transdiscipline informing science: From ugly duckling to swan," CIT. Journal of computing and information technology, vol. 7, no. 3, pp. 213-219, 1999. 